\title{
Characterization of the Dielectric Properties of the Tommy Atkins Mango
}

\author{
Paulo F. Silva Júnior ${ }^{1}$ (D), Ewaldo E. C. Santana ${ }^{1}$ (D), Mauro S. Silva Pinto ${ }^{1}$ (D) Everson P. Andrade E $^{\text {(D) }}$, \\ Joabson N. Carvalho ${ }^{2}$ (D), Raimundo C. S. Freire ${ }^{3} \mathbb{D}$, Maciel A. Oliveira ${ }^{3}$, Elder E. Carneiro de \\ Oliveira ${ }^{4}$ (D) \\ ${ }^{1}$ Universidade Estadual do Maranhão/Programa de Pós-Graduação em Engenharia de Computação e Sistemas \\ (PECS),pfs1224@gmail.com, ewaldoeder@gmail.com, maurosergiospinto@gmail.com \\ ${ }^{2}$ Instituto de Educação, Ciência e Tecnologia da Paraíba/ Grupo de Telecomunicações e Eletromagnetismo \\ Aplicado (GTEMA), eversonandrade76@gmail.com, joabsonnogueira@gmail.com \\ ${ }^{3}$ Universidade Federal de Campina Grande/Coordenação de Pós-Graduação em Egenharia Elétrica \\ (COPELE),rcsfreire@gmail.com, maciel.ifpb@gmail.com \\ ${ }^{4}$ Universidade Estadual da Paraíba, elder2@ymail.com
}

\begin{abstract}
This paper presents the characterization of dielectric properties (dielectric permittivity and dielectric loss factor) of Tommy Atkins mango (Mangifera indica $L$ ), a fruit produced in several regions of Brazil, of great economic importance. The fruits were characterized according to their maturation index, by probe method, and identified by the yellowish tone in their bark. The results allowed correlating the dielectric characteristics of the fruit with the physicochemical transformations that occurred in the maturation process of the mango Tommy. It was also verified a greater variation in the frequencies below $1 \mathrm{GHz}$, with the maturation indicated by the dielectric signature on the fifth day after the harvest. From these results, we can observe the use of electromagnetic materials and techniques in the solution and optimization of processes in agriculture can improve the quality of products consumed or suggesting best practices to the productive sector.
\end{abstract}

Index Terms - Dielectric characterization; Tommy Atkins mango; dielectric properties; maturation identification.

\section{INTRODUCTION}

The dielectric properties of food and other materials constitute an area of knowledge with an important potential for the development of new methodologies for characterization, quality evaluation and monitoring of food processing using non-destructive techniques. The method is based on the interaction of an external field applied with the electric dipole moment of a sample of the material, being often expressed as a function of the electrical permittivity. The method is based on the interaction of an applied external field with the electric dipole moment of a sample of the material, and is often expressed as a function of the electrical permittivity [1].

This characterization method has been used to identify several food parameters that present higher quality and presentation demands, reducing losses and improving negotiation margins, as well as identifying possible food quality problems. Regarding agricultural production, the cultivation of small fruits has attracted the attention of producers, traders and consumers in the local market, since the fact is the result of the diffusion of information on the characteristics and properties of these species and is 
a direct consequence of globalization of food consumption habits, including fruits [2], [3].

The specialized literature presents several studies of the dielectric properties of various foods, in different ranges of frequencies and temperatures, obtained by different measurement methods. The results are presented for liquid foods such as grape juice, pineapple, apple, pear and orange, green coconut water and citrus juice, honey, milk [4]-[8], Soy beverages, grapes and sugar solutions, grape juice [9]-[11]. Studies on semi solid foods, such as mashed potatoes, butter, cheese, and mango puree are also observed [12]-[14].

Most researchers are looking for solutions for the development of online meters that, in the microwave range, determine the electrical characteristics of agricultural products as indicators of other properties (moisture content, specific mass, pest control, temperature and glucose concentration) [15], [16]. The dielectric characterization of fruits and plants for commercial use becomes an option to identify essential characteristics of the materials, and this information can be used to improve the logistics process, such as storage and transportation, as well as the marketing and the consumption. One of these characteristics is the time of fruit ripening after harvest. One form of identification is the color of the skin and the density observed by the touch on the fruit, but these evaluations are susceptible to errors, as both the color and the touch on the fruit may indicate a false positive. Another factor is the indication of the ripening period after harvest, so from the dielectric characterization it is possible to assess, with greater certainty, the total maturation period of the fruit, thus deciding on the best storage time, method of transport, time for commercialization, and consumption. Thus, the use of the dielectric characterization method applied in fruits has indications both in the scope of academic research and in the indication of possible solutions in the sectors of production, storage, transportation, commercialization and consumption, being an important research line with practical applications.

The present work aims to characterize the Tommy Atkins mango (Mangifera indica L), using the coaxial line technique to measure the values of the relative dielectric constant and also the dielectric loss factor.

This paper is composed of five more sections besides this introduction. Section II discusses the dielectric properties of materials, section III presents the most common methods used to determine the dielectric properties, section IV presents the materials and methodology used in this work, in section $\mathrm{V}$ the results are discussed and in Section VI the final considerations and the steps that will give continuity to the work are carried out.

\section{MATERIALS AND Methodology}

\section{A. Dielectric Properties of Materials}

The behavior of electric or magnetic fields and electromagnetic waves in materials depends fundamentally on the geometry and electromagnetic parameters of the medium.

Relative electrical permittivity represents the ability of the material, in the food case, to absorb and 
store energy, in response to an applied electric field. This property has influence in the reflection of the waves (in borders) and the attenuation of the waves inside the materials [17]. In the frequency domain, the permittivity $\left(\varepsilon_{r}^{*}\right)$ of the material assumes a complex value, its value is presented relative to the vacuum permittivity value, and:

$$
\varepsilon_{r}^{*}=\varepsilon_{r}^{\prime}-j \varepsilon_{r}^{\prime \prime}
$$

The real part, known as "relative dielectric constant" $\left(\varepsilon_{r}^{\prime}\right)$, represents the ability of the material, in the food case, to store energy, in response to an applied electric field, already the imaginary part of (1), known as "dielectric loss factor" (F/m). Refers to the energy dissipated as heat [18].

Equation (1) suggests that the quantities $\varepsilon^{\prime}$ and $\varepsilon^{\prime \prime}$ are lagged between each other. The angle representing this lag, known as the "loss tangent" $(\tan \delta)$, is an important estimator of the dielectric characteristics of the medium. Is the ratio of the lost energy to the stored energy per cycle of the applied external field. In numerical terms, the loss tangent is represented by:

$$
\operatorname{tg}(\delta)=\varepsilon^{\prime \prime} / \varepsilon^{\prime}
$$

The propagation of an electromagnetic wave is controlled by the electrical and magnetic properties of a propagation medium and also the frequency of the applied magnetic field. These properties are affected by other factors, such as material composition, temperature and the oscillation frequency of the electromagnetic field [18].

We also find similar effects related to magnetic fields, but not considered in this work due to nonvariation of this parameter in the material considered.

Another important parameter in the characterization of the dielectric properties of materials is the Electrical Conductivity $(\sigma)$, which represents the ability of the material to "conduct" electric current. "Non-dielectric" materials (finite conductivity) have free electrons in their crystalline lattice, which can travel with the passage of electric current or due to the presence of an external field. The conductivity of the material will act on the dielectric loss of the applied field [19].

Some methods are used to determine the complex electrical permittivity of materials, among them:

1) Parallel plates: The sample is placed between parallel plates, as in a capacitor. The capacitance value is measured and the permittivity is calculated.

2) Coaxial test method: A coaxial transmission line is terminated with the material that is desired to determine the permittivity, which serves as a load. Permittivity is determined by the spreading parameters measured at the inlet of the line.

3) Cavity disturbance technique: Uses a resonant cavity operating in the fundamental TE or TM 
mode. It is based on displacement of the cavity resonance frequency due to the insertion of a sample of the material into the TM cavity.

4) Transmission in the free space: In this method, two separate antennas can be used at a certain distance in a controlled environment. A sample of the material is placed between two antennas. Permittivity is determined from the spreading parameter.

The choice of method to be used depends on the accuracy, frequency range, availability of equipment, among others.

In this paper, the coaxial test technique has used, as it is the determination of the dielectric characteristics of a sample of semisolid material in a frequency range above $1 \mathrm{GHz}$.

\section{B. Methodology of the Measurements}

In this work, 52 (fifty-two) samples of Tommy Atkins mango were used, with the fruit in different stages of maturation. The fruits used in the experiment were acquired from the same orchard, where the characteristics of cultivation, irrigation, pruning and harvesting were as homogeneous as possible, seeking to ensure equivalence between the analyzed products. Each sample has identified and correlated to the maturation stage by the percentage of the yellowish color in relation to the green color [20]. According [21] the determination of the maturation stage for harvest varies according to the type of market to which the fruits are destined. Table 1 shows the fruits used in project and lists the samples used in this work and their respective stages of maturation according to the percentages of fruit ripening were estimated as described in [21].

TABLE I. MATURATION OF SAMPLES

\begin{tabular}{|c|c|c|c|}
\hline Visual Color & $\begin{array}{l}\text { Predominant } \\
\text { Color }\end{array}$ & $\begin{array}{l}\text { Days After } \\
\text { Harvest }\end{array}$ & Sensory Characteristics \\
\hline 1 & Dark Green & 1 & $\begin{array}{l}\text { High stiffness. Coloring the shell with shades of green } \\
\text { and red. }\end{array}$ \\
\hline 2 & Light Green & $2-3$ & $\begin{array}{l}\text { Less stiffness. Reduction of red color and green tint in } \\
\text { the bark. }\end{array}$ \\
\hline 3 & $<30 \%$ Yellow & $4-5$ & $\begin{array}{l}\text { Less firmness of the fruit compared to the previous } \\
\text { stage. Most of the fruits begin to have a yellowish color. }\end{array}$ \\
\hline 4 & $30-70 \%$ Yellow & $6-8$ & $\begin{array}{l}\text { Intense aroma of the fruits. Reduction of firmness } \\
\text { compared to the previous stage. Start of the senescence of } \\
\text { some fruits of the sample. }\end{array}$ \\
\hline 5 & $>70 \%$ Yellow & $8-10$ & $\begin{array}{l}\text { The fruits are yellowish in color, with a decrease in } \\
\text { firmness and in the beginning of the rind. No uniformity } \\
\text { was observed in the samples. }\end{array}$ \\
\hline
\end{tabular}


The measurements were performed in the laboratory of the Telecommunications and Applied Electromagnetism Group (GTEMA) of the Federal Institute of Education, Science and Technology of Paraiba (IFPB). After being divided into $3 \mathrm{~cm}^{2}$ sections, the samples were taken to an analytical balance and the weights determined in their initial states, in nature. The experiments were conducted at room temperature $\left(26^{\circ} \mathrm{C}\right)$, which was kept constant throughout the experiment. The measurements of the relative dielectric constant $\left(\varepsilon_{r}^{t}\right)$ and the relative dielectric loss factor $\left(\varepsilon_{r}^{r s}\right)$ were performed on the Agilent vector network analyzer (VNA), model 16451B (300 kHz - $20 \mathrm{GHz}$ ), through Dielectric Probe Software 85070. Fig. 1 shows the setup of the measured dielectric characteristics of the Tommy Atkins mango (Mangifera indica L), where it can be observed that the probe is in contact with the shell, being aligned with the barycenter of the fruit.

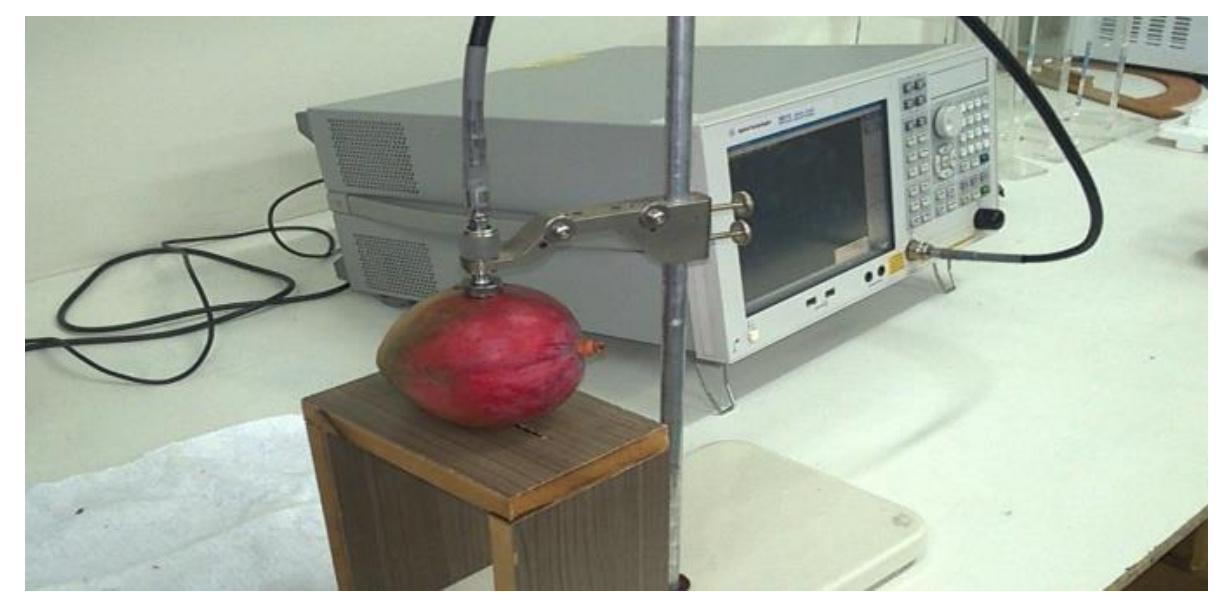

Fig. 1. Measured setup of the dielectric characteristics of Tommy Atkins mango (Mangifera indica L).

\section{RESULTS}

Maturation of the fruit produces greater concentration of water, promoting the variation of its dielectric characteristics. Fig. 2 shows the variation of dielectric characteristics of Tommy Atkins mango 1 in the period of nine days, for the dielectric permittivity. We noted that the variation observe can be attributed by variation of the water inside the fruit in period.

We noted that the behavior of the dielectric constant variation is not uniform over the days, with reductions and increase of this parameter being observed during the observation period. The variations can be attributed to the differences in metabolism observed in the mango during the maturation process. 


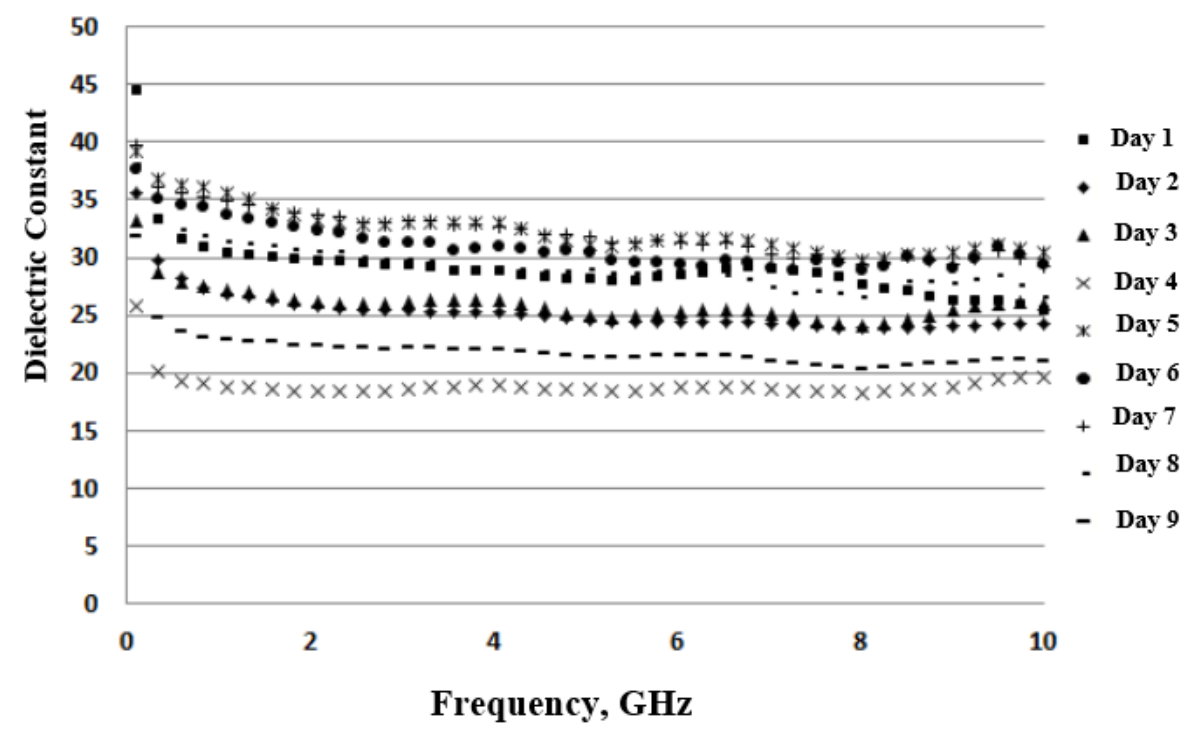

Fig. 2. Comparison of dielectric constant by frequency of Tommy Atkins mango in nine days.

For a better correlation of the values of the dielectric constant with the maturation phases of the fruit, the values were presented as a function of the measurement day, as shown in Fig. 3.

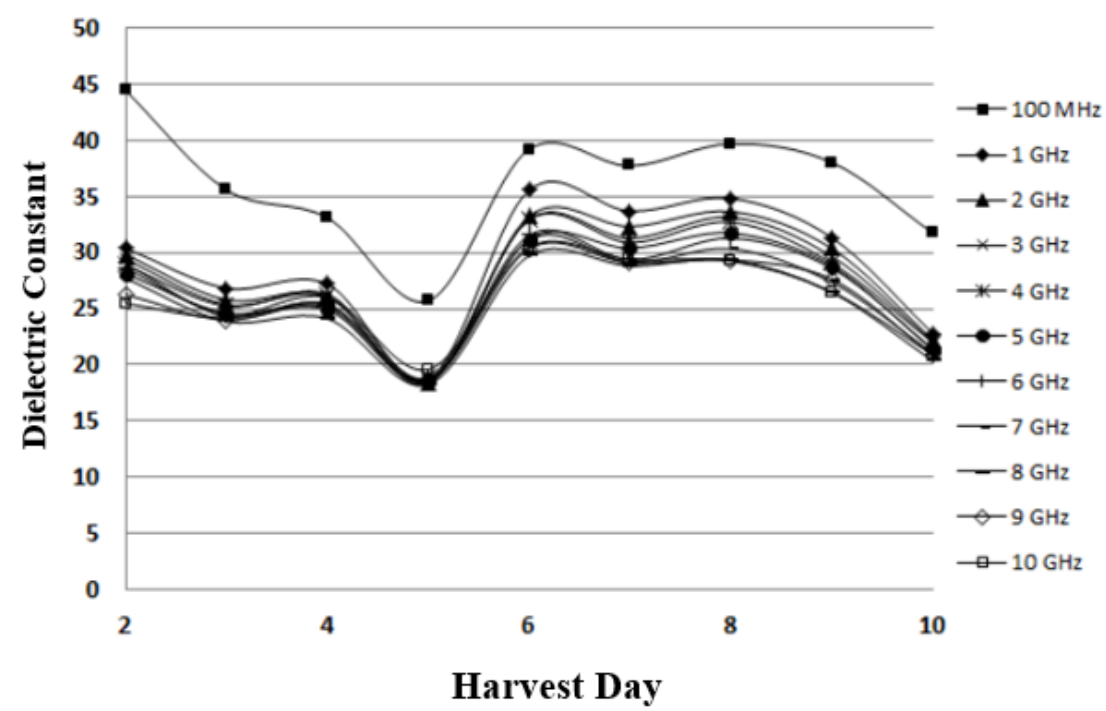

Fig. 3. Diary variation of the measured dielectric constant of Tommy Atkins mango.

In this way by the variation of the dielectric constant we can observe the "signature" of the dielectric constant for the sleeve Tommy Atkins. It is observed that until the fifth day after harvest, for the conditions in which the fruits were kept, the maturation peak occurred. The first post-harvest days coincide with the pre-climacteric phase, with lower respiration rate and low metabolic activity. During this period a small oscillation in the dielectric constant value was observed throughout the range, with the lowest value in all measurements occurring exactly on the fifth day after harvest. From then on, a significant increase in the dielectric constant can be observed. At this stage, the fruit presents the characteristics of intense aroma and less rigidity in the sensorial analysis. 
From the eighth day of measurement, some fruits already showed signs of senescence, with the beginning of the destruction of their tissues. In this period, there was a considerable drop in the dielectric constant, being higher in some specific frequencies. A similar behavior was observed with the loss tangent values shown in Fig. 4.

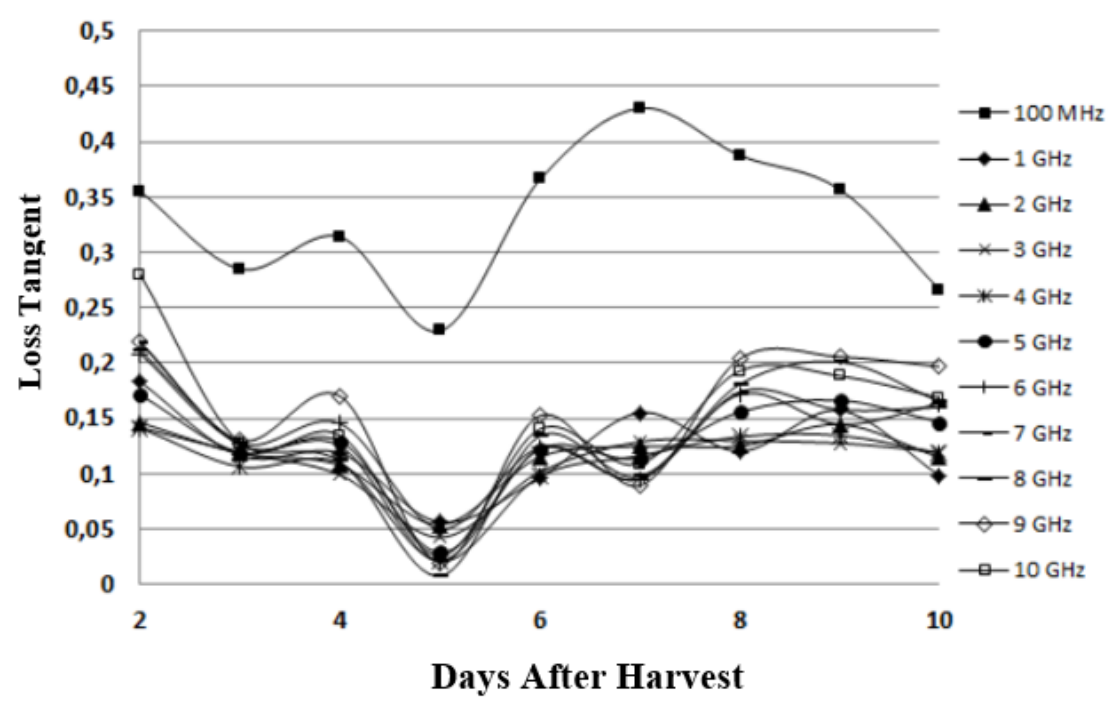

Fig. 4. Variation of the loss tangent of Tommy Atkins mango by days after harvest.

From the results of the dielectric characterization of Mango Tommy it can be observed that fruit ripening happens on the fifth day after harvest, regardless of fruit coloration or sensory analysis. Thus the logistics, marketing, sale and consumption of the product must take into account that for the increase of the term for use of the good quality some attitudes can be considered, among them, we can mention: the freezing of the fruit, making the process maturation is slowed down; faster transportation or even the change of routes or vehicles used to transfer the product.

\section{FINAL CONSIDERATIONS}

Characterization of dielectric properties (dielectric permittivity and dielectric loss tangent) of Tommy Atkins mango (Mangifera Indica L), a fruit produced in the state of Paraíba and other regions of Brazil, of great economic importance, is presented in this paper. In measurements was used the probe method, performed on Vector Network Analyzer 16451B, through software Dielectric Probe 85070. The fruits were characterized according to their maturation index, identified by the yellowish tone in their bark. The results allowed correlating the dielectric characteristics of the fruit with the physicochemical transformations that occurred in the maturation process of the mango. The highest variations of the dielectric parameters occurred in the climacteric phase, where the highest rate of fruit metabolism occurs. It was also verified a greater variation in the frequencies below $1 \mathrm{GHz}$, with the maturation indicated by the dielectric signature on the fifth day after the harvest, indicating that the activities of logistics, marketing and consumption should be optimized so that the execution time of their activities is optimized for better use of the fruit. From these results we can observe the use of 
electromagnetic materials and techniques in the solution and optimization of processes in agriculture can improve the quality of products consumed or suggesting best practices to the productive sector.

\section{ACKNOWLEDGMENT}

We thank the Group of Telecommunications and Applied Electromagnetism - GTEMA and the Coordination of the Graduate Program in Electrical Engineering of the Federal Institute of Paraiba (PPgEE) - Campus João Pessoa for the availability of equipment and facilities that enabled the execution of this work, and post-graduate in Computer Engineering and Systems (PECS) of the State University of Maranhão (UEMA).

\section{REFERENCES}

[1] S. O. Nelson, "Dielectric spectroscopy studies on fresh fruits and vegetables," In Antennas and Propagation Society International Symposium, IEEE, pp. 455-458, 2005.

[2] M. E. Sosa-Morales, L. Valerio-Junco, A. Lopez-Malo, H. S. Garcia, "Dielectric properties of food: Reported data in the 21st century and their potential Applications", Food Science and Technology, vol. 43, pp. 1169-1179, 2010.

[3] P. C. A. Junior, P. C. Corrêa, D. M. Queiroz, "Armazenamento e Processamento de Produtos Agrícolas, " Revista Brasileira de Engenharia Agrícola e Ambiental, vol. 4, no. 3, pp. 403-408, 2000.

[4] X. Zhu, W. Guo, X. Wu, "Frequency and temperature dependent dielectric properties of fruit juices associated with pasteurization by dielectric heating", Journal of Food Engineering, 109, pp. 258-266, 2012.

[5] A. P. F. Peñata, Estudo das propriedades dielétricas de água de coco verde e sucos de frutas cítricas relevantes para o aquecimento por micro-ondas. Tese de doutorado, Escola Politecnica Universidade de São Paulo, São Paulo, 2015.

[6] W. Guo, Y. Liu, X. Zhu, S. Wang, "Temperature-dependent dielectric properties of honey associated with dielectric heating," Journal of Food Engineering, vol. 102, pp. 209-216, 2011.

[7] T. Kudra, G. Raghavan, C. Akyel, R. Bosisio, F. Van De Voort, "Electromagnetics properties of milk at its constituents at 2.45 GHz", International Microwave Power, vol. 27, no. 4, pp. 199-204, 1992.

[8] X. Zhu, W. Guo, Y. Jia, F. Kang, F, "Dielectric properties of raw milk as functions of protein content and temperature," Food Bioprocess Technol, vol. 8, no. 3, pp. 670-680, 2015.

[9] P. Coronel, J. Simunovic, K. P. Sandeep, P. Kumar, "Dielectric properties of pumpable food materials at $915 \mathrm{MHz}$ ". International Journal of Food Properties, vol. 11, pp. 508-518, 2008.

[10] T. N. Tulasidas, G.S. Raghavan, F. Van de Voort, R. Girard, "Dielectric properties of grapes and sugar solutions at 2.45 GHz", International Microwave Power Institute, vol. 30, no. 2, pp. 117-123, 1995.

[11] A. Garcia, J. L. Torres, E. Prieto, M. De Blas, "Dielectric properties of grape juice at 0.2 and 3 GHz", Journal of Food Engineering, vol. 48, n. 3 pp. 203-211, 2001.

[12] D. Guan, M. Cheng, Y. Wang, and J. Tang. "Dielectric properties of mashed potatoes relevant to microwave and radiofrequency pasteurization and sterilization processes," Journal of Food Science-Chicago, vol. 69, no.1, pp. 30-37, 2004.

[13] C. D. Everard, C. C. Fagan, C. P. O’Donnell, "Dielectric properties of process cheese from 0.3 to 3 GHz," Journal of Food Engineering, vol.75, pp. 415-422, 2006.

[14] A. F. R. L. Cruz, J. A. W. Gut, C. C. Tadini, "Propriedades dielétricas do purê de manga cru nas frequências de 0,5 a 3 ghz entre as temperaturas de 10 e $90^{\circ}$ c," COBEQ, Congresso Brasileiro de Engenharia Química. XX, Florianópolis SC, outubro, 2014.

[15] K. J. Soares, "Propriedades dielétricas de semente de mamão," Dissertação de Mestrado, Centro de Ciências e tecnologias Agropecuárias da Universidade Estadual do Norte Fluminense Darcy Ribeiro, Campo dos Goytacazes - RJ, Março, 2014.

[16] H. A. Marhabadi, A. Enayati, H. Aliakbarian, M. A. Soltaru, and M. Moghavvemi. "Electromagnetic solutions for the Agriculture Problems," Advanced Microwave Circuits and Systems, Ed. V. Zhurbenko. In Tech, 2010, pp. 471-490.

[17] "IEEE Guide for Measurements of Electromagnetic Properties of Earth Media," in IEEE Std 356-2001 (Revision of IEEE Std 356-1974), 2002.

[18] F. Içier, T. Baysal, "Dielectric properties of food materials 1: Factors affecting and industrial uses," Critical Reviews in Food Science and Nutrition, vol. 44, pp. 465-471, 2004.

[19] "Condutividade Elétrica," Universidade do Estado de Santa Catarina - UDESC Centro de Ciências Tecnológicas CCT Departamento de Química - DQM FQE0001 Físico-Química Experimental Exp. 09 Condutividade Elétrica. [ONLINE]. Disponivel: file:///C:/Users/Andr\%C3\%A9cia/Downloads/09_Condutividade.pdf Acesso em 11 Março 2016.

[20] J. D. Motta, A. J. M. Queiroz, R. M. F. Figueiredo, K. S. M. Sousa, "Índice de cor e sua correlação com parâmetros físicos e físico-químicos de goiaba, manga e mamão," Revista Comunicata Scientiae, vol.6, no.1, pp.74-82, ISSN: 2177-5133, Janeiro/Março, 2015.

[21] "O cultivo e o mercado do mamão," Serviço Brasileiro de Apoi às Micro e Pequenas Empresas - SEBRAE [ONLINE]. Disponivel: http://www.sebrae.com.br/sites/PortalSebrae/artigos/O-cultivo-e-o-mercado-do-mam\%C3\%A3o, Acesso em 01 de Abril 2016. 